\title{
Torsional displacement ratio of frame-tube structure under expected rare earthquake
}

\author{
X.M. Chen ${ }^{1, a}$, J. Duan, Y.G. Li \\ ${ }^{1}$ China state construction technical center, Beijing, China \\ aHanee@126.com
}

Keywords: time-history, elasto-plasticity, frame-tube structure, torsional displacement ratio

Abstract. Columns in frame-tube structures may be damaged easily because of the torsional response, therefore, torsional displacement ratio was defined by national codes for spectrum analysis under frequent earthquake. For analysis of time-history under expected rare earthquakes, different from displacement angle, it isn't essential for the checking of torsional displacement. Numerical simulation indicates that torsional response cannot be embodied by displacement angle in nonlinear time-history analysis. As columns in a frame-tube structure may be damaged earlier than being expected by the transfinite torsional displacement ratio, and then the performance of double fortification lines for earthquake may be decreased, the structural torsional response should be considered together with the displacement angle.

\section{Introduction of torsional displacement ratio}

Seismic disasters of both domestic and overseas show that irregularity of building planar, shortage of tortional stiffness and eccentricity of mass and stiffness would lead to much more serious structural damage. Structural tests of vibration table also showed that excessive torsional deformation would make the damage deteriorate, therefore, the parameter named torsional displacement ratio was introduced by national codes, which was defined as Fig.1

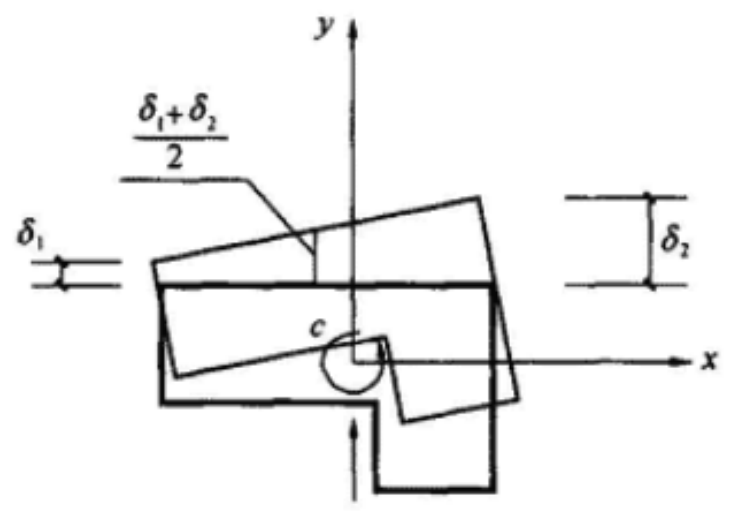

Fig.1 Definition of torsional displacement ratio

As the floor shown in Fig. 1, the torsional displacement ratio of $y$ direction under earthquake can be formulated as follow:

where

$$
R_{d}=\frac{2 \delta_{2}}{\delta_{1}+\delta_{2}}
$$

$R_{d}$ is the torsional displacement ratio;

$\delta_{1}$ is the minimum displacement in $y$ direction;

$\delta_{2}$ is the maximum displacement in $y$ direction。

Torsional displacement ratio was defined with the ratio of maximum value to average value of horizontal displacement of those vertical members under specified seismic force. It should better be little than 1.2 and must not greater than 1.4 [1]. Xu's[2] research indicated that the ratio of maximum displacement to minimum value could reach to 3.0 with the relationship of torsional displacement 
ratio equal to 1.5 and it would increase much more rapidly as the torsional displacement ratio exceeding 1.8. Professor Fang[3] discussed the relationship between torsional displacement ratio and period ratio, which is the other parameter for controlling structural torsional response. Based on the spectrum method proposed by the national codes, professor Qian[4] presented a method based on elastic time-history analysis, Zheng[5] researched the displacement ratio in pushover analysis.

In this paper, torsional displacement ratio was researched for analysis of elastic-plastic time-history with numerical methods, numerical results show that envelops of displacement angle can hardly exhibit the structural torsional response, in order to avoid torsional damage, structural torsion deformation should be analyzed together with displacement angle.

\section{Static analysis}

A 32-floor frame-tube structure shown in Fig.2 was analyzed with fortification intensity equal to eight, and the critical columns damaged by torsion were denoted in Fig.2(b).

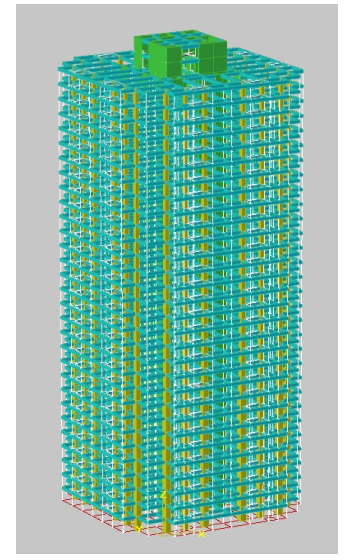

(a) Structural model

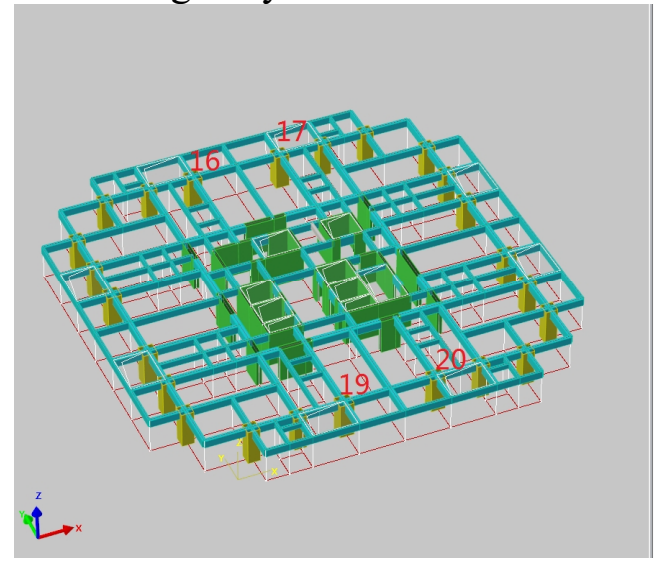

(b) Model Tor1.07

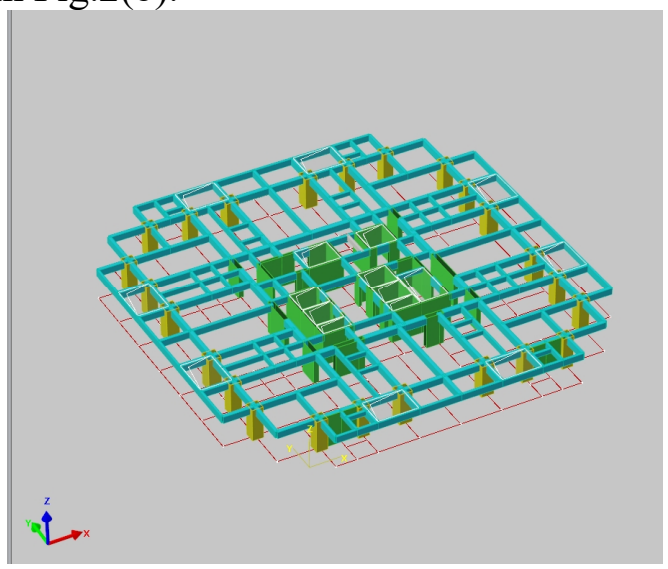

(c)Model Tor1.27

Fig.2 Model of frame-tube structure

To research the influence of torsional displacement on structural performance under expected rare earthquakes, two additional pieces of shear wall were deployed at downside and the shear wall at the top was removed as shown in Fig.2(b) and Fig.2(c).

Results of mass and natural periods are listed in Tab.1. The maximum displacement angles and torsional displacement ratios in $x$ direction are listed in Tab.2.

Tab.1 Mass and natural periods

\begin{tabular}{|c|c|c|c|c|}
\hline Model & Mass(Ton) & T1(s) & T2(s) & T3(s) \\
\hline Tor1.07 & 43576.781 & 2.486 & 2.382 & 2.333 \\
\hline Tor1.27 & 43892.160 & 2.445 & 2.393 & 2.304 \\
\hline
\end{tabular}

Tab.2 Maximum displacement angles and torsional displacement ratios

\begin{tabular}{|c|c|c|}
\hline Model & DispAngle_X(Flr) & DispRatio_X(Flr) \\
\hline Tor1.07 & $1 / 746(15)$ & $1.07(1)$ \\
\hline Tor1.27 & $1 / 733(11)$ & $1.27(1)$ \\
\hline
\end{tabular}

Results in Tab.1 show that the change of periods and mass can be negeligible. Results in Tab.2 show that the displacement angle of model Tor 1.27 increased about $2 \%$, but the torsional displacement ration increased about $20 \%$.

\section{Elastic-plastic time-history}

The constitutive relationship of damaged plasticity is used for concrete[7,8] and the damp ratio is assumed to be 0.05 , rebar is assumed as kinematic hardening with damp ratio equal to 0.02 . The uniaxial skeleton curve of compression and relative damage curve can be formulated with Eq.2 and Eq.3 respectively: 


$$
\begin{gathered}
\sigma=\left(1-d_{c}\right) E_{c} \varepsilon \\
d_{c}= \begin{cases}1-\frac{\rho_{c} n}{n-1+x^{n}} & x \leq 1 \\
1-\frac{\rho_{c}}{\alpha_{c}(x-1)^{2}+x} & x>1\end{cases}
\end{gathered}
$$

The structure was loaded with the seismic wave shown in Fig.2 and the time-history lasted for $20 \mathrm{~s}$.

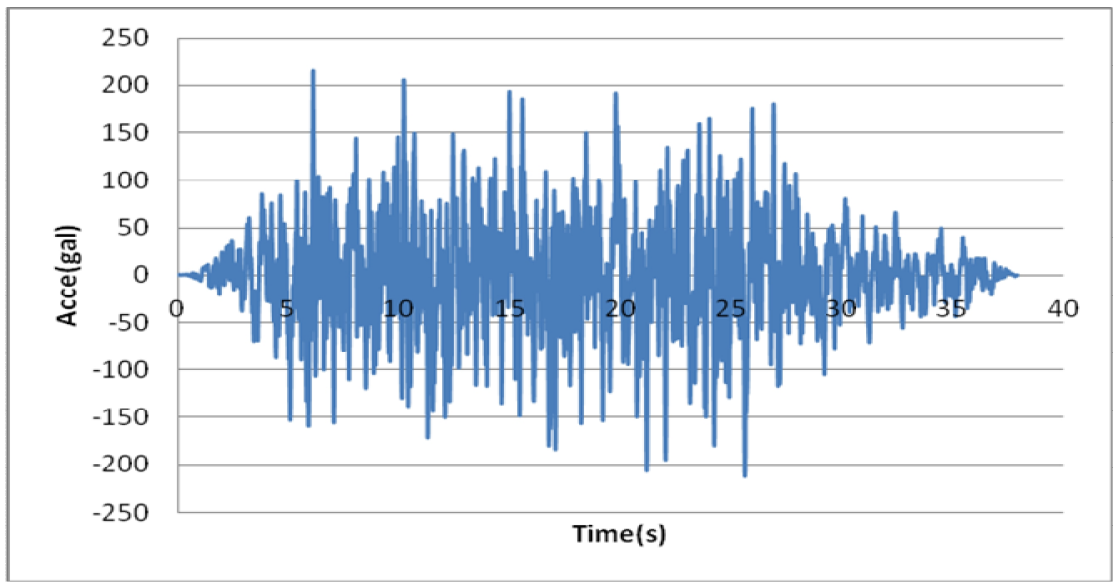

Fig.3 Seismic wave

\section{Numerical results}

1. Displacement angle

Envelops of displacement angle for both models are shown in Fig.4:

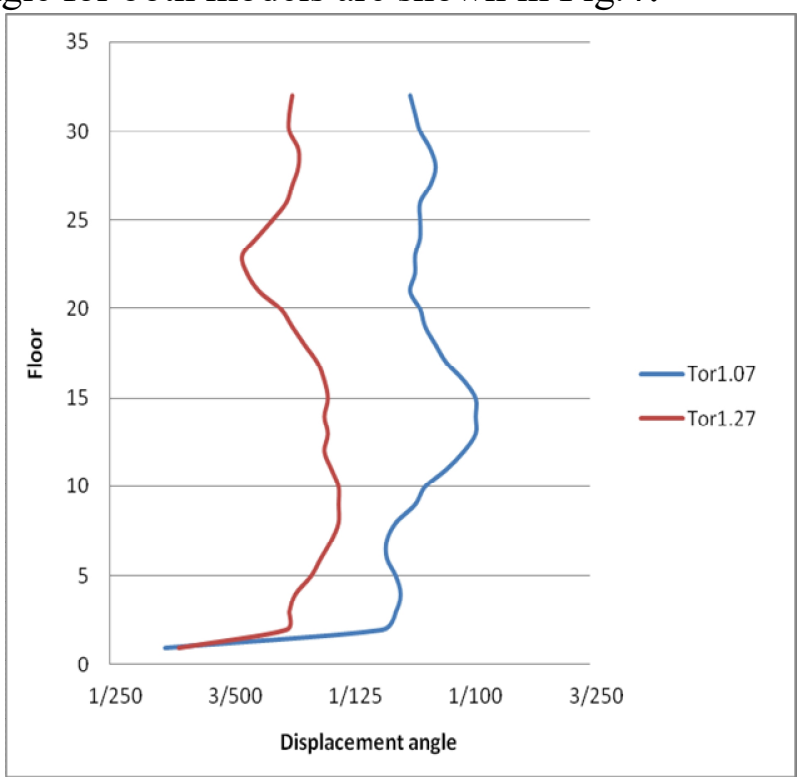

Fig.4 Max displacement angle of the floors

Under rare earthquake, displacment angles of model Tor1.07 are much greater than Tor 1.27 except the first floor, so it seemed that model Tor1.27 should be more safety, which is quite different with the results of spectrum analysis under frequent earthquake.

2. Maximum and minimum value of horizontal displacement

For the first floor with maximum of torsional displacement ratio, horizontal displacement time-histories of both maximum and minimum are shown in Fig.5(a), time-histories of their difference is also shown in Fig.5(b). 


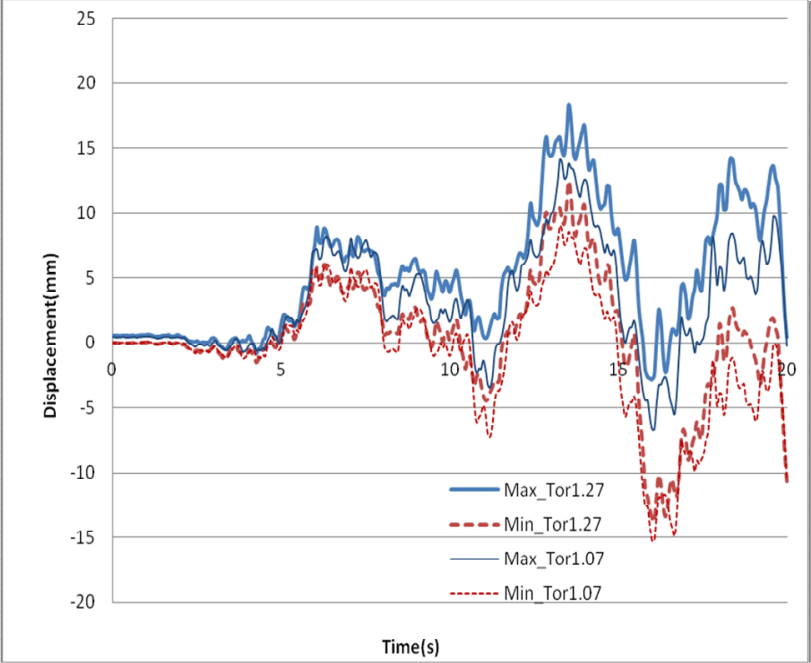

(a) Maximun and minimum displacement

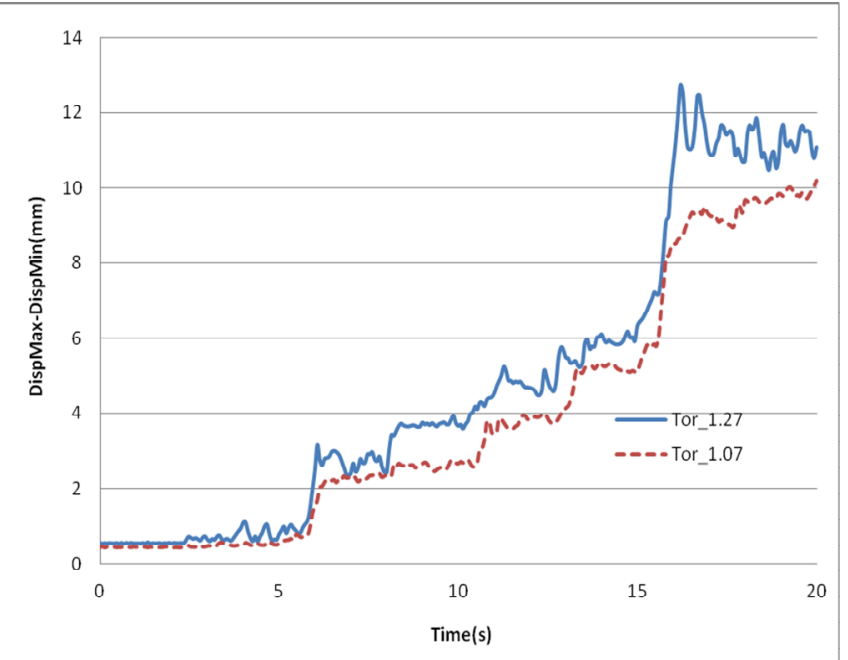

(b) Difference of Maximum and minimum

Fig.5Time-histories of displacement of first floor in $x$ direction

Curves in Fig.5 show that the torsional deformation of model Tor1.27 is much more significant than model Tor1.07 especially 15 seconds later.

3. Concrete compression damage

As most of the failures for concrete structure are due to material damage, thus the difference of horizontal displacements shown in Fig.5 should be traced to concre compression damage or plastic strain of rebars.

Concrete damage is more important than plastic strain of rebars, therefore, time-histories of concrete compression damage were presented in Fig.6 for those columns denoted in Fig.2.
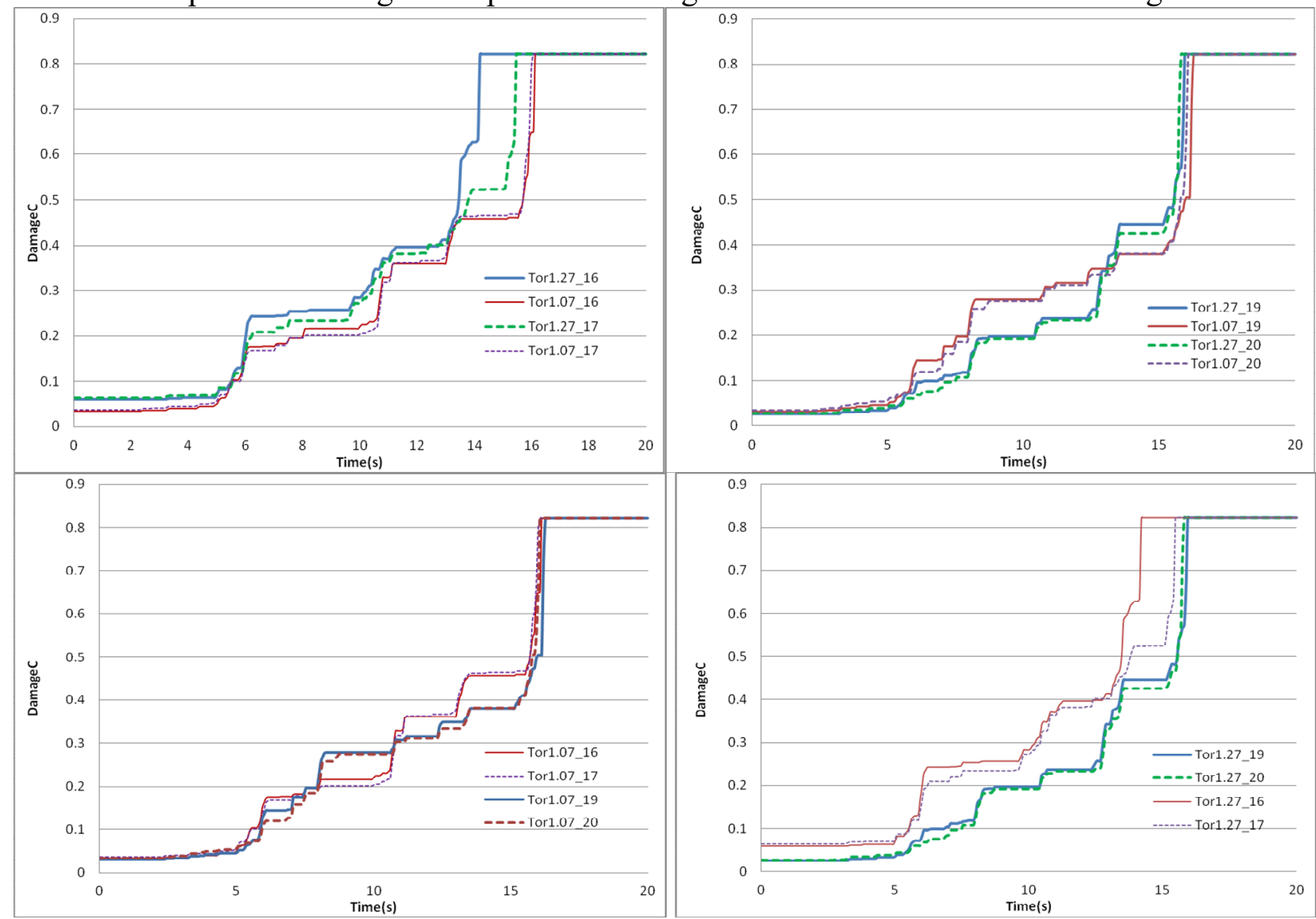

Fig.6 Time-histories of concrete compression damage

As the key members for torsional moment, columns of $16^{\text {th }}$ and $17^{\text {th }}$ in model Tor1.27 were damaged earlier than model Tor 1.07 , but it is opposite for $19^{\text {th }}$ and $20^{\text {th }}$. For time-history of damage in 
the same model, significant difference is only available in model Tor1.27 between upside columns and downside columns.

4. Time-history of base shear force

With the damage of key members, the load bearing capacity of different models can be compared with the time-histories of base shear force as shown in Fig.7.

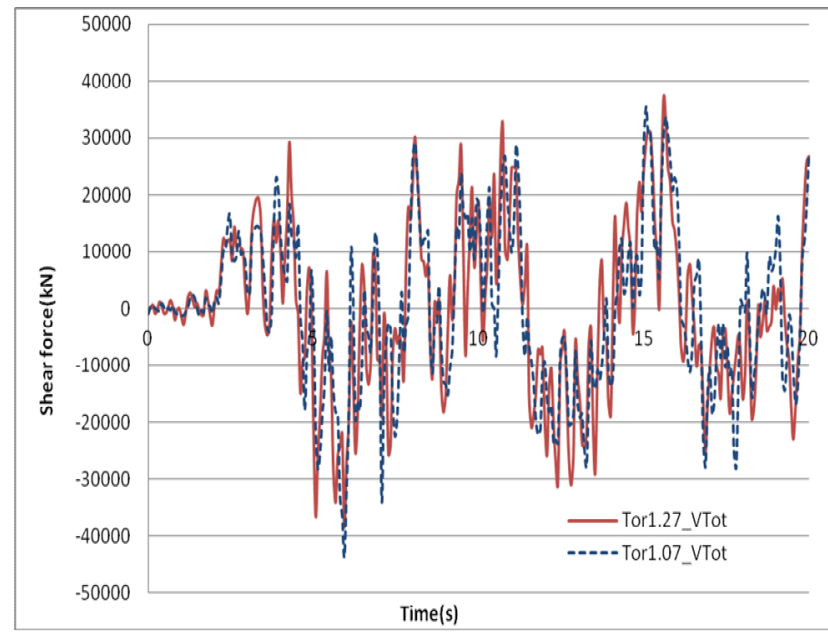

(a)Total shear force

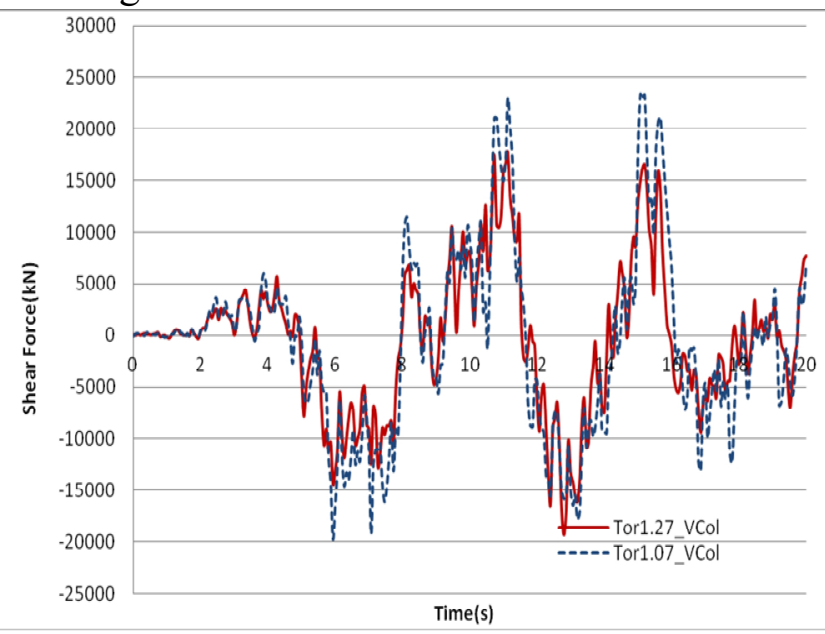

(b) Column shear force

Fig.7 Time-histories of shear force at $x$ direction

It can be seen that shear force carried by columns in model Tor1.27 is lower than the other model becase of the damage of columns induced by torsional deformation. Acctually, premature damage of frames in a frame-tube structure may even destroy the double fortification lines of earthquake.

\section{Conclusions}

In analysis of elastic-plastic time-history, the maximum displacement angle was used as the critical principle to avoid structural collapse under expected rare earthquakes. Compared with displacement angle, torsional displacement ratio was only defined in spectrum analysis for frequent earthquakes. Researches show that torsional response under expected rare earthquakes may not be embodied by displacement angle, and it may lead to serious damage of some key members and then the structure may be damaged before we expected. For a frame-tube structure, the double fortification lines may even be destroyed, therefore, the structural torsion in rare earthquakes should be considered together with the displacement angle.

\section{References}

[1] China architecture \& building press. Technical specification for concrete structures of tall building, Beijing, China, 2010.

[2] Xu Peifu, Huang Jifeng, Wei Chengji. Control of torsional response of tall building structures. China Civil Engineering Journal, 2006, 39(7): 1-8.

[3] Fang Ehua, Cheng Maokun. Discussion of torsion resistance control method for structures in current design code. Building Structure, 2005,35(11):12-15.

[4] Qian Jiaru, Jiang Yun. Study on calculating methods of displacement ratio used to judge structural torsion irregularity. Building Structure, 2006,36(12):79-81.

[5] Zheng Jiandong, Fang Zhongjun, Dai Xiaoying. Comparative analysis on different methods of a high-rise building torsion displacement ratio adjustment. Building Structure, 2011, 41(S1): 608-610.

[6] China architecture \& building press. Code for design of concrete structures, Beijing, China, 2010.

[7] ABAQUS Inc(2016). ABAQUS User Manual, V2016. 